\title{
Social Determinants of Maternal and Child Undernutrition in Cambodia: A Systematic Review
}

Pheak Chhoun

Khuondyla Pal

Sreymom Oy

Candice Collins

Sovannary Tuot

See next page for additional authors

Follow this and additional works at: https://touroscholar.touro.edu/cehs_pubs

Part of the International Public Health Commons, and the Maternal and Child Health Commons

\section{Recommended Citation}

Chhoun, P., Pal, K., Oy, S., Collins, C., Tuot, S., \& Yi, S. (2016). Social Determinants of Maternal and Child Undernutrition in Cambodia: A Systematic Review. International Journal Of Food And Nutritional Science, 3 (2), 331-337. https://doi.org/10.15436/2377-0619.16.881

This Article is brought to you for free and open access by Touro Scholar. It has been accepted for inclusion in by an authorized administrator of Touro Scholar. For more information, please contact touro.scholar@touro.edu. 


\section{Authors}

Pheak Chhoun, Khuondyla Pal, Sreymom Oy, Candice Collins, Sovannary Tuot, and Siyan Yi 


\title{
Social Determinants of Maternal and Child Undernutrition in Cambodia: A Systematic Review
}

\author{
Pheak Chhoun ${ }^{1,2^{*}}$, Khuondyla Pal ${ }^{1}$, Sreymom Oy ${ }^{3,4}$, Candice Collins ${ }^{5}$, Sovannary Tout ${ }^{1}$, Siyan Yi ${ }^{1,5}$ \\ ${ }^{1}$ Center for Population Health Research, KHANA \\ ${ }^{2}$ School of Health Science, Flinders University, South Australia \\ ${ }^{3}$ Southeast Asian Ministers of Education Organization Regional Centre of Food and Nutrition (SEAMEO RECFON) University of \\ Indonesia, Jakarta, Indonesia \\ ${ }^{4}$ Department of Nutrition, Faculty of Medicine, University of Indonesia, Jakarta, Indonesia \\ ${ }^{5}$ Public Health Program, College of Education and Health Sciences, Touro University California, USA
}

*Corresponding author: Pheak Chhoun, No. 33, Street 71, Phnom Penh, Cambodia, P.O Box 2311, Phnom Penh 3, Mobile: (855)12-995-866; Tel: +855-23-211-505; Fax:+855-23-214-505; Email: cpheak@khana.org.kh / pheak.chhoun@gmail.com

\begin{abstract}
Background: Maternal and child undernutrition is one of the major contributors to the increasing of overall disease burden and mortality in the globe and Cambodia. Therefore, a systematic literature review was conducted to identify social determinants of maternal and child undernutrition in Cambodia.

Methods: Systematic literature search was performed through journal databases including ProQuest Central, Scopus, PubMed, Medline (Ovid), Google scholar, and World Health Organization Statistical Information System (WHOSIS). Keywords were used to search for literature in English published from 2003 to 2015. Content analysis was conducted among final selected papers.

Results: In total, 25 articles met the inclusion criteria and were selected for the review. The prevalence and social determinants of maternal and child undernutrition were two emerged themes found in this review. In 2010, 19\% of non-pregnant women aged 15 - 49 years were underweight (body mass index $<18.5 \mathrm{~kg} / \mathrm{m}^{2}$ ). This rate had not been significantly improved significantly compared to the rate in 2000 when the rate was reported at $21 \%$. The prevalence in rural and urban areas was $20 \%$ and $17 \%$, respectively. Among under-5 children, $45 \%$ of them were stunted, $11 \%$ were wasted, and $29 \%$ were underweight. Six social determinants of maternal and child undernutrition were identified including poverty, income inequity, food insecurity, low maternal education, infections, and gender inequity.

Conclusions: The prevalence of maternal and child undernutrition in Cambodia remains relatively high and varies across geographical areas. The intervention programs should be carefully designed to improve maternal and child undernutrition in the country taking social determinants identified in this study into consideration.
\end{abstract}

Received Date: April 25, 2016

Accepted Date: July 27, 2016

Published Date: August 6, 2016

Citation: Chhoun, P., et al. Social Determinants of Maternal and Child Undernutrition in Cambodia: A Systematic Review. (2016) Int J Food Nutr Sci 3(2): 331-337.

DOI: $10.15436 / 2377-0619.16 .881$

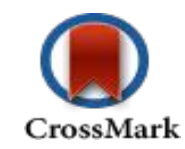

Keywords: Social determinant; Maternal and child health; Undernutrition; Cambodia

\section{Introduction}

Maternal and child undernutrition has been broadly recognized as a major public health concern in most parts of the world due to its contribution to the increase of overall burden of diseases and mortality ${ }^{[1-3]}$. Globally, nutrition-related factors are estimated to contribute to approximately $35 \%$ of child deaths and $11 \%$ of the total global disease burden ${ }^{[3,4]}$. Furthermore, 2.2 million deaths and $21 \%$ of disability-adjusted life-years (DALYs) for children less than five years of age are due to stunting, severe wasting, and restriction of intrauterine growth ${ }^{[3]}$. In addition, poor nutritional status of pregnant women may result in chronic iron deficiency which accounts for a great amount of deaths ${ }^{[5]}$.

Copyrights: (C) 2016 Chhoun, P. This is an Open access article distributed under the terms of Creative Commons Attribution 4.0 International License. 
Undernutrition is associated with various social and physical factors. Singh et al. found that having a mother with low body mass index (BMI), child's age, higher birth order and poor living standard are the risk factors of undernutrition among children in rural area of eastern $\mathrm{Nepal}^{[6]}$. Household food insecurity and infections ${ }^{[7]}$ as well as low maternal education ${ }^{[8]}$ also impact on child nutritional status. A study conducted in rural areas of Madhya Pradesh State in India found that hygienic practices, birth weight, home delivery, and complementary feeding practices are significantly associated with undernutrition among infants ${ }^{[9]}$. More importantly, a multivariate analysis by Rahman et al. has shown that severe and moderate wasting among children were significantly associated with maternal BMI, mother's media exposure, child's age and birth size, and respiratory sickness in childhood ${ }^{[10]}$.

The World Health Organization (WHO) states that women entering into the labour force can also lead to maternal and child undernutrition ${ }^{[11]}$. If the mother does not have access to adequate child care, the child is less likely to receive regular feedings with proper nutrition leading to undernutrition ${ }^{[11]}$. Women in the labour force exert more energy during the day, however, due to some cultural norms; their husbands may get the cash they earned. This leads to less money spent on food consumption and may eventually compromise their nutritional status $^{[11]}$. Also, work is one of the leading reasons women choose to not breastfeed, which is one of the most prominent practices fighting against undernutrition in children ${ }^{[11]}$. Ultimately, this study points to inequity of income for women. If a woman chooses to go to work, they can jeopardize their and their child's nutritional status. However, the decreased income of a household by the mother not having a job can also adversely affect their and their child's health.

Globally, children are considered malnourished if they are stunted, wasted, or underweight. Stunted children refers to those who is below average height for their age; wasted refers to a child who has a below average weight for their height; and underweight is a child who has below average weight for their age. United Nations Children's Fund (UNICEF), WHO, and World Bank estimated that $38 \%$ of children under five in low income countries were moderate or severe stunting; $22 \%$ were moderate or severe underweight; and $9 \%$ were moderate or severe wast$\mathrm{ed}^{[12]}$. A cross-sectional study in Iran found the prevalence of stunted, underweight, and wasted among children under five to be $10 \%, 10 \%$, and $8 \%$, respectively ${ }^{[13]}$. The main determinants of malnutrition found in the study were income, maternal education, access to health services and safe water supply, gender, settlement area, family size, and ethnicity ${ }^{[13]}$.

Undernutrition among mothers and children is also a known underlying cause of maternal and child mortality in Cambodia. According to the Cambodian Demographic and Health Survey (CDHS) published in 2014, 32\% of children less than five year of age were chronically malnourished (stunted); $24 \%$ were underweight; and 10\% were wasted ${ }^{[14]}$. Between 2000 and 2005, maternal mortality rate in Cambodia remained stable at 472 per 100, 000 live births, and child mortality rate remained very high reaching at 83 per 1000 live births ${ }^{[15]}$. Maternal malnutrition, underweight and wasting, suboptimal breastfeeding or micronutrient deficiencies contributed to 6,170 deaths of children under five years of age in Cambodia, representing $60.4 \%$ of all childhood mortality ${ }^{[16]}$. Specifically in Cambodia, undernutri- tion is estimated to contribute to around $45 \%$ of child deaths ${ }^{[17]}$. Children who suffer undernutrition in their first 1,000 days of life are more susceptible to diseases, and have restricted cognitive development that may lead to reduced productivities and poorer economic outcomes in later life ${ }^{[17]}$.

Although there are some informative studies on maternal and child malnutrition, it is important to identify specific social determinants of maternal and child undernutrition in Cambodia in order to inform intervention programs to address this important public health issue. We conducted a systematic literature review to estimate the prevalence and identify social determinants of maternal and child undernutrition in Cambodia. We also attempted to understand the existing policies and intervention programs addressing this problem in the country. This information may help policy makers to understand and draw an attention in improving maternal and child undernutrition with effective interventions focusing on social determinants of the problem.

\section{Methods}

A systematic literature search was thoroughly conducted in April 2013 to explore the prevalence and social determinants of maternal and child undernutrition and identify applicable strategies in improving maternal and child nutritional status and preventing undernutrition in mothers and children in Cambodia $^{[18]}$. The following databases were searched: ProQuest Central, Scopus, PubMed, Medline (Ovid), Google scholar, and WHOSIS (World Health Organization Statistical Information System). Hand searches were also conducted to identify grey literature including publications and reports from the Ministry of Health and the Ministry of Planning in Cambodia, and the websites of the United Nations organizations and International Non-Governmental Organizations such as the Food and Agriculture Organization ${ }^{[19]}$, the World Bank, UNICEF, WHO, and Helen Keller International (HKI).

English-language articles published between 2003 to 2013 with information related to the social determinants of maternal and child undernutrition in Cambodia were included. The following medical subheading $(\mathrm{MeSH})$ terms and key words were used: mother, child, health, malnutrition, undernutrition, social determinants, intervention, strategies, and Cambodia. Additionally, Boolean Operator 'AND' and 'OR' were used in combination with MeSH terms and key words. The additional literature search was conducted for the period of 2014 to 2016.

The selected literatures were analyzed through all the contents. The analyses included relevant aspects of social determinants of maternal and child undernutrition in Cambodia to generate relevant emerging themes, including policies, programs, and interventions addressing this issue.

\section{Results}

A total of 159 articles were identified from all databases, and 25 articles $^{[14-17,20-57]}$ met the inclusion criteria for analyses. The additional search found 23 articles from PubMed but only 5 articles ${ }^{[58-62]}$ were selected to analyse. From the total of 30 articles, two types of articles, including estimates of the prevalence of maternal and child undernutrition, and social determinants of maternal and child undernutrition, were identified. 
In the social determinants of maternal and child undernutrition, six subthemes including poverty, income inequity, food security, mother's education, infection, and gender inequity, were identified. Details of themes and subthemes are described below.

\section{Prevalence of maternal and child undernutrition}

Maternal undernutrition is highly prevalent in Cambodia. Undernutrition in women is defined as poor nutritional status of women aged 15 - 49 years, or BMI less than 18.5 $\mathrm{Kg} / \mathrm{m}^{2[20]}$. In $2010,19.1 \%$ of Cambodian women aged $15-49$ years were underweight $\left(\mathrm{BMI}<18.5 \mathrm{~kg} / \mathrm{m}^{2}\right.$ ). Prevalence rates remained relatively unchanged between 2000 and 2005 reported at $21 \%$ and $20 \%$, respectively ${ }^{[14]}$. This problem has been inequitably distributed between rural and urban areas of Cambodia with the estimated prevalence of $20 \%$ in rural and $17 \%$ in urban $\operatorname{areas}^{[14]}$.

Similarly, the prevalence of child undernutrition in Cambodia also remained high. Child undernutrition is indicated by three main indicators including stunting (low height-forage), wasting (low weight-for-height), and underweight (low weight-for-age $)^{[21]}$. According to the National Institute of Statistics, Cambodian children aged under five years old experienced stunting, wasting, and underweight approximately at $45 \%, 11 \%$, and $29 \%$, respectively ${ }^{[14]}$. Stunting is an indication of chronic undernutrition in children in particular among those aged under five years. It is inequitably distributed in urban and rural areas of Cambodia- $42 \%$ in rural areas and $28 \%$ in urban areas ${ }^{[22]}$. Micronutrient deficiencies among stunted infants and toddlers in Cambodia were prevalent at $73 \%$ in Zinc deficiency, $71 \%$ in anemia and $28 \%$ in Vitamin A deficiency ${ }^{[23]}$. Furthermore, prevalence of underweight in children under five years in Cambodia remained stable after decreasing from $38 \%$ in 2000 to $28 \%$ in 2005 and $2010^{[14]}$. The latest prevalence rate of underweight children in Cambodia stands in the third highest rate among South East Asian nations after Lao PDR (32\%) and Myanmar (30\%) $)^{[24]}$.

High prevalence of maternal and child undernutrition in Cambodia might be associated with inadequate food consumption, and limitation of resources in improving nutritional status. Bachmeyer (2009) has inferred an inadequate food to less amount of food consumption, unhealthy food or unbalanced diet, and inappropriate mealtime behaviors, such as tantrums ${ }^{[25]}$. The National Institute of Statistics found that Cambodian people in average consumed $1,770 \mathrm{Kcal}$ a day which is less than the Minimum Dietary Energy Requirement (MDER). A gap between an average of dietary energy needs and the average of dietary energy consumption is defined as 'food gap' estimated at $744 \mathrm{Kcal} /$ person/day for Cambodian population. The estimated MDER for rural areas is slightly less than urban areas which reported at 1,762 and $1804 \mathrm{Kcal} /$ person/day, respectively ${ }^{[26]}$. Culturally, Cambodian families especially poor households, prioritise men who are the head of household and the main income earner for better food than women and children ${ }^{[27]}$. Thus, this food gap probably greater affects women and children who require more nutritious food for their reproductive process and physical growth than men ${ }^{\text {page } 277 .}$

Similar to many other developing countries, Cambodia has very limited resources to improve women and children's nutritional status ${ }^{[28]}$. These limitations include lacking of geographic information on maternal and child undernutrition, lack of human resources and low funding. Yet, an efficient effort in allocating these resources had not been seriously taken into account in this country ${ }^{[28]}$.

\section{Social determinants of maternal and child malnutrition}

Maternal and child undernutrition in Cambodia is in part determined by social factors that include poverty ${ }^{[29-31]}$, income inequality ${ }^{[22,31]}$, food insecurity ${ }^{[26,27,32]}$, mother's education $^{[33,34]}$, parasitic and infectious diseases ${ }^{[2,35]}$, and gender inequity $^{[33,36]}$. The details of each theme are discussed below.

Poverty: Poverty has largely attributed to maternal and child undernutrition in Cambodia. It influences individuals' food choices and preferences and subsequently their nutritional status ${ }^{[37]}$. The poverty rate in Cambodia remains one of the highest among developing countries, with approximately $23 \%$ of the total population still living below the poverty line of less than USD1.25 per capita per day ${ }^{[38]}$. Many poor households have a limited chance to consume nutritious food, access to clean water, or utilize health care services, which contributes to the increasing of undernutrition among women and children in the country ${ }^{[29,39]}$. A study cited in the New Public Health by Frank Baum published in 2007 showed that $20 \%$ of low-income parents have been hungry in the previous month due to lack of money $(2007$, p. 282). It also showed that $65 \%$ of children under five years of age, as well as more than $50 \%$ of parents, had poor diets. A lack of household assets is associated with higher child malnutrition, in particular a higher prevalence of stunting and underweight ${ }^{[30,31]}$. One study showed that the reduced prevalence of stunting seen between 2000 and 2010 was highly influenced by improvement in household wealth ${ }^{[40]}$. Poor hygiene and sanitation is also associated with poverty levels and can lead to malnutrition. Compared to $32 \%$ of children whose households had an improved toilet, $48 \%$ of Cambodian children under 5 years from households with unimproved toilets were stunted ${ }^{[22]}$.

Inequity of income: Income disparities and poverty affect the maternal and child nutritional status in Cambodia, as low income affects nutrition and food choices ${ }^{[31,37]}$. As household wealth increases, the prevalence of undernutrition decreases, especially among women and children ${ }^{[22,31,33]}$. In other words, if women and children live in low- income families, their risk of undernutrition is higher. In Cambodia, 25\% of children live in households in the poorest wealth quintile, while only $16 \%$ live in households in the richest wealth quintile ${ }^{[22]}$. Another study has found that $25 \%$ children who lived in low-income households were reported by caregivers to be in fair, poor, or very poor health ${ }^{[41]}$. Therefore, programs that work on achieving better nutrition in children need to target low-income households.

In Cambodia in 2009, income and other factors were associated with inequality in access to food for $28 \%$ of urban and $26 \%$ of rural households ${ }^{[26]}$. A higher proportion of female-headed households experienced food insecurity than male-headed households, accounting for $28 \%$ and $26 \%$, respectively. Poverty and income inequality in Cambodia are more likely due to disparity of employment status between men and women and between urban and rural areas. According to the Cambodian Demographic Health Survey (CDHS) 2010, men tended to be employed more than women (81\% versus 70\%) (CDHS, 2010). The employment rate of women in urban and rural areas is about equally distributed (66\% and $70 \%$, respectively). Thus, employ- 
ment may have some indirect influence on nutritional status and direct effect on economic growth. Historical evidence shows that economic growth generally leads to improvement in human nutrition. It is the most obvious and direct pathway from economic growth to improved nutrition via household income ${ }^{[27]}$. If this growth contributes to increase income at household level, people are able to consume more food with higher nutritional value. Thus, income has a strong effect on maternal and child undernutrition.

Food insecurity: Food insecurity is one of the most significant social determinants contributing to maternal and child malnutrition. Food insecurity is defined as a situation of lacking secure access to sufficient amount of food which is safe and nutritious for growth and development of an active and healthy life ${ }^{[26]}$. Studies found that $25 \%$ of households in Cambodia experienced food insecurity which included low quality and continuity of food access and dietary diversity in food consumption ${ }^{[2,35]}$. Lacking sufficient amount of safe and nutritious food may lead to undernutrition in particular for women and children. Healthy nutrition is fundamental for physical, psychological, and mental growth and development for children, and productivity for adults, especially women in reproductive age ${ }^{[27]}$.

Food insecurity can be referred to as an inappropriate food intake for individual and household level. It includes insufficient amount of food consumption, unhealthy food or not balanced diet, and inappropriate mealtime ${ }^{[25]}$. In 2008, only $49 \%$ of children aged $6-23$ months received appropriate complementary feeding in terms of minimum times, dietary diversity, and breast milk or milk products ${ }^{[35]}$. Anderson et al. claimed that inappropriate snacks and eating without adult supervision cause malnutrition among toddlers in Cambodia ${ }^{[32]}$. They also found that poor nutritional practice of parents in preparing additional food for their children is another contributing cause of toddlers' malnutrition in urban Cambodia. Parents commonly prepare mixed porridge consisting of rice, salt, and sugar as an additional food for their toddlers and start providing supplementary food to their infants beginning when their children are aged 3 - 4 months, before the recommended introduction time of six months for solid foods ${ }^{[32,42]}$. These inappropriate behavioral practices in infant feeding may affect their current and later nutritional status. Therefore, ensuring food security at individual and household levels is crucial to reduce the prevalence of maternal and child undernutrition.

Low mother's education: Education is recognized as one of social determinants of health ${ }^{[43]}$ and may influence undernutrition in women and children. A review by Miller and Rodgers showed that greater education attainment of mothers contributes to new skills, beliefs, and choices about sound health and nutritional practices, which directly determines nutritional status of themselves and their children ${ }^{[33]}$. In 2010, 16\% of Cambodian women had no education, $78 \%$ attained only primary education, and only $7 \%$ finished their secondary or higher education ${ }^{[44]}$. Low level of education of women results in poor nutritional status of both mothers and children ${ }^{[22,45]}$. They also found that $22 \%$ of children of mothers who attended secondary school were stunted, compared to $46 \%$ of children whose mothers had no education $^{[33]}$.
Infectious diseases: It is argued that undernutrition among women and children are also an issue of diseases ${ }^{[35]}$. Diseases and poverty have a reciprocal relationship when it comes to undernutrition. Being affected by a disease may cause loss of income which in turn amounts for lowered amounts of food resulting in undernutrition. On the other hand, being impoverished means lowered quality and quantity of food purchased which could lead to undernutrition and cause diseases. It is believed that maternal and child undernutrition in Cambodia has been impacted by parasitic infections and other infectious diseases. For example, malaria and fever contribute to high level of malnutrition $^{[2,35]}$. Parasitic infestation can cause micronutrients deficiency as it diverts nutrients from the body and can lead to blood loss and anemia ${ }^{[35]}$. As undernourished children have an increasingly high risk of getting sick and greater severity of disease, prevention and treatment of childhood infections and other diseases should be effectively taken into account ${ }^{[35]}$.

Gender inequities: There is increasing recognition of gender as one of the important determinants of health for women and children $^{[43]}$. Beyond biological differences, gender roles, social norms and behaviors have an influence on the way that women, men, girls and boys are capable of accessing health services, in addition to how health care systems respond to their needs ${ }^{[36]}$. A few studies have addressed the relationship between gender as an environmental factor and maternal and child undernutrition $^{[33,36]}$. However, in Cambodia, there was no significant difference in the three indicators of undernutrition in male and female children under five years old. Cambodian girls were slightly less likely be stunted than boys; $35 \%$ of girls classified as stunted compared to $38 \%$ of boys, while rates of wasting were not statistically significant different for girls and boys ${ }^{[33]}$.

There was no specific literature that directly discussed gender disparities in adult women, which would impact on maternal undernutrition in Cambodia. However, cultural aspects such as a hierarchal structure that exists in many cultures including Cambodian culture, allow fathers to be served at meals first in which they would eat the best food before their children ${ }^{[36]}$. This could lead to wasting and undernutrition in younger girls which can later affect their reproductive health and cause maternal health issues ultimately contributing to the intergenerational cycle of malnutrition. This same hierarchal structure could impact the maternal nutrition because women tend to serve themselves last.

\section{Discussion}

\section{Maternal and child undernutrition interventions}

Maternal and child undernutrition remains one of the major public health challenges in Cambodia. It is highly prevalent in both rural and urban areas, and contributes to maternal and child mortality in this country. We identified interventions and programs implemented to improve nutritional status specifically for women and children aged less than five years. Four programs were identified in the literature considered to be effective interventions for improving maternal and child undernutrition in Cambodia. First, homestead food production program aimed to increase the consumption of micronutrient-rich foods for women and children in Cambodia ${ }^{[46]}$. A home-based treatment of acute malnutrition program was an evidence-based, commu- 
nity level rehabilitation program for children with moderate and acute malnutrition. It was a combination of nutrition education, regular home visits, and food support intervention ${ }^{[47]}$. Another program was 'micronutrient intervention' for children that was a strategic intervention for vitamin A supplementation, preventive zinc supplements, iron supplement for children ${ }^{[45]}$, and universal promotion of iodized salt ${ }^{[48]}$. Finally, 'nutrition education program' was another interesting program that provided nutrition education and counseling in health facilities, community or at home. It aims at modifying the habitual dietary intake in increasing nutritious food consumption ${ }^{[49]}$.

We have learnt that these programs were implemented, but they seem to be executed in a small scope and targeted to only individual and household levels. According to Labonte's model, these interventions tend to focus on medical and behavioral model more than socio-environmental model ${ }^{[50]}$. Overall, it has shown that the programs change behavioral practices in food consumption, food preparation and food production at individual and household level within a small coverage. However, these programs should be expanded to a national coverage. Interventions should target more at upper stream ${ }^{[37,51]}$ or socio-environmental model ${ }^{[50]}$ in order to ensure sustainability of the interventions. A previous study showed that the scaling up of improved sanitation facilities, reducing or eliminating maternal tobacco use, and increasing the amount of time between births would reduce the prevalence of stunting ${ }^{[40]}$. We believe this would also reduce the other aspects of malnutrition. Also, creating or improving programs with public health initiatives, such as improving drinking water, will assist in decreasing the prevalence of undernutrition in Cambodia.

\section{Policy implication:}

There were two interesting policies which are relevant to maternal and child malnutrition in Cambodia, including the national social protection strategy ${ }^{[52]}$ and a conditional cash transfer program for women who live in poverty ${ }^{[33]}$. These policies have been considered as enablers to the improvement of maternal and child undernutrition in the country. They have helped to ensure the equal opportunity in accessing nutritious foods, health care services and education between children in rural and urban settings.

Men et al. argued that malnutrition is among the most salient factors causing poverty in Cambodia ${ }^{[36]}$. This argument could be true as the economic costs of undernutrition include direct costs like an increased burden on the health care system, and indirect costs such as losing productivity. Moreover, it has been estimated that only childhood anemia alone is associated with a $2.5 \%$ drop in adult wages annually ${ }^{[35]}$. Therefore, poverty and undernutrition is reversely the cause of each other. These facts can be used in argument for policies to be implemented to prevent malnutrition and undernutrition.

Various social determinants of maternal and child undernutrition need different approaches to address from medical, behavioral and socio-environmental approaches ${ }^{[50]}$. Miller, and Rodgers and Pandey, S., et al. suggest that increasing school enrolment by targeting scholarship program for girls could possibly increase self-perception on nutrition and health care ${ }^{[33,53]}$. The disparity in education contributes to undernutrition among women and children across Cambodia. Furthermore, reducing the burden of disease in Cambodia, especially the incidence of infectious disease among the poor, can be addressed by improving health care service. However, there was lack of policy on subsidising cost on health care for women and children in Cambodia which resulted in an increase of infectious disease ${ }^{[54]}$. For example, malaria and HIV/AIDS which are more or less influencing the nutritional status of women and children. The government and other relevant stakeholders should develop a healthy policy on maternal and child malnutrition and coordinate multi-sectoral response for its implementation. This policy may need to include some elements of health promotion legislation, such as creating supportive environment, building community capacity and empowerment and developing sustainable resources ${ }^{[51,55]}$ which may help to address social determinants of maternal and child undernutrition in Cambodia.

Food insecurity: While undernutrition plays a role not only as an enabler of poor quality of life, but also a barrier of good health and development ${ }^{[56]}$, food security is more likely to be the intervention which requires collective actions at all level including individual, household, national, regional and global scales in addressing undernutrition ${ }^{[27]}$. Eliminating food and nutrition insecurity in Cambodia should be one of the most prioritized interventions for Cambodian government and all stakeholders, with comprehensive and integrated approaches focusing on food availability, access, utilization, and stability ${ }^{[27]}$. A central approach to reduce prevalence of undernutrition is to ensure food security, which refers to the situation that all people have physical, social and economic access to sufficient, safe and nutritious food at all times for their dietary requirements and preferences in their active and healthy life ${ }^{[27]}$. Interventions related to food security should be comprehensive and interested at micro and macro levels.

Food security and nutrition are taking place at the front position of discussions among Cambodia's policy-makers. Policy-makers have incorporated food security and nutrition-related goals and objectives in national strategies and frameworks such as the Cambodia Nutrition Investment Plan 2003 - 2007, the Cambodia Millennium Development Goals, the Rectangular Strategy and the National Strategic Development Plan 2006 - 2010 ${ }^{[27,57]}$. However, greater attention needs to be paid in addressing the issues. The attention on health care costs, distance and transport, availabilities of health personnel and drugs in health care facilities for early intervention of the problem are crucial $^{[36]}$.

Further research: Although there are many informative studies on maternal and child undernutrition Cambodia, further research is necessary to inform all stakeholders to implement the comprehensive interventions. There was a suggestion to examine the specific components of micronutrients which help improving child's nutrition in Cambodia and to assess how much more-educated mother should be empowered to make better choices about their children's food and health care. In addition, it is recommended for an exploration on the association of mother's stature and BMI with her children's nutritional status and the role of health care in children's nutritional outcomes ${ }^{[33]}$. It is also important to explore micronutrient fortification in the ricebased diets ${ }^{[32]}$ in order to improve nutritional status. Analyze the relationship of maternal and child undernutrition in Cambodia and other social determinants such as access to health care ser- 
vices and other public service, transportation, employment and housing is also needed ${ }^{[43]}$. The outcome of this research will contribute towards more comprehensive and effective interventions to reduce undernutrition among women and children.

\section{Conclusions}

Following the same pattern as other developing countries, maternal and child undernutrition has been recognized as a critical underlying cause of maternal and child mortality in Cambodia. The prevalence of maternal undernutrition has remained relatively high over the past 15 years and is differentially distributed between rural and urban areas. The prevalence of child undernutrition is also relatively high among Southeast Asian nations. The prevalence of three major indicators of undernutrition among children under 5 years was estimated at $45 \%$ for stunting, $11 \%$ for wasting and $29 \%$ for underweight.

Poverty, income inequity, food insecurity, mother's education, infection and lack of vaccination, and gender inequities are key social determinants contributing to maternal and child undernutrition in Cambodia. Poverty affects access to sustainable, safe and nutritious food at the individual, household and national levels. Poverty and food insecurity directly contribute to the high prevalence of undernutrition and are complementary causes. Mother's education, infection and gender inequities are more likely influential in food choices, food access and health care.

Cambodia requires more supportive interventions, and an enabling environment to improve maternal and child undernutrition. Social determinants of this issue should be addressed in ensuring food security and development of healthy public policy. Analysis on relationship of maternal and child undernutrition in Cambodia and other social determinants of health including access to public service, employment, transportation and housing are highly recommended.

Acknowledgements: The authors thank KHANA Center for Population Health Research for their endless support. Special thanks are deserved to Dr. Lilian Mwanri, School of Health Science, Flinders University, South Australia and Ms. Emily Treleaven for their excellent advices and proof reading.

Competing Interests: The authors declare that they have no competing interests.

Authors' Contributions: PC managed the literature review, designed the study, developed the systematic review proposal, conduct literature search, analyzed the literatures, and prepared the manuscript. All authors contributed in planning the study, analyses and writing up the manuscript.

\section{References}

1. Bhutta, Z.A., Ahmed, T., Black, R.E., et al. What works? Interventions for maternal and child undernutrition and survival. Lancet 371(9610): 417-440.

2. Pasricha, S.R., Biggs, B.A. Undernutrition among children in South and South-East Asia. (2010) J paediatr child health 46(9): 497-503.

3. Black, R.E., et al. Maternal and child undernutrition: global and regional exposures and health consequences. (2008) Lancet 371(9608): 243-260.
4. United Nations Children's Fund UNICEF-WHO, World Health Organization, and World Bank Joint Child Malnutrition Estimates. (2012) UNICEF, New York; WHO, Geneva: The World Bank, Washington, DC.

5. AbouZahr, C. Global burden of maternal death and disability. (2003) Br med bull 67(1): 1-11.

6. Pramod Singh, G.C., Nair, M., Grubesic, R.B., et al. Factors associated with underweight and stunting among children in rural Terai of eastern Nepal. (2009) Asia Pac J Public Health 21(2): 144-152.

7. Wolde, M., Berhan, Y., Chala, A. Determinants of underweight, stunting and wasting among schoolchildren. (2015) BMC public health 15: 8 .

8. Bharati, S., Pal, M., Chakrabarty, S., et al. Trends in socioeconomic and nutritional status of children younger than 6 years in India. (2011) Asia Pac J Public Health 23(3): 324-340.

9. Meshram, I.I., Kodavanti, M.R., Chitty, G.R., et al. Influence of Feeding Practices and Associated Factors on the Nutritional Status of Infants in Rural Areas of Madhya Pradesh State, India. (2013) Asia Pac J Public Health 27(2): 1345-1361.

10. Rahman, A., Chowdhury, S., Hossain, D. Acute malnutrition in Bangladeshi children: levels and determinants. (2009) Asia Pac J Public Health 21(3): 294-302.

11. Hawkes, C. Globalization, Food and Nutrition Transitions. Globalization and Health Knowledge Network: Research Papers. (2007) WHO Commission on Social Determinants of Health.

12. United Nations Children's Fund, World Health Organization, and The World Bank, UNICEFWHO-World Bank Joint Child Malnutrition Estimates (2012): UNICEF, New York; WHO, Geneva; The World Bank, Washington, DC.

13. Kavosi, E., et al. Prevalence and determinants of under-nutrition among children under six: a cross-sectional survey in Fars Province, Iran. (2014) Int J Health Policy and Mang 3(2): 71-76.

14. Cambodia Demographic and Health Survey 2010. (2011) National Institute of Statistics, Directoriat General for Health, and ICF Macro [Cambodia] and Calverton, Maryland, USA.

15. National Nutrition Program, National Nutrition Strategy 20092015, M. (2008) National Centre for Maternal and Child Health.

16. Bagriansky, J., et al. The economic consequences of malnutrition in Cambodia, more than 400 million US dollar lost annually. (2014) Asia Pac J Clin Nutr 23(4): 524-531.

17. Undernutrition in the land of rice - why there should be a nutrition goal in the post-2015 framework, the case from Cambodia. (2014) Results UK.

18. Saks, M., Judith. A. Researching health: qualitative, quantitative and mixed methods. (2007) Sage Publications Ltd.

19. Michael C. L Human nutrition in the developing world. (1997) FAO Cooperate Document Repository.

20. Ergo, A., Shekar, M., Gwatkin, D.R. Inequalities in Malnutrition In Low- and Middle-Income Countries: Updated and Expanded Estimates (2008).

21. de Onis, M., Monteiromm C., Akré, J., et al. The worldwide magnitude of protein-energy malnutrition: an overview from the WHO Global Database on child growth. (1993) Bulletin of the world health organization 71(6): 703-712.

22. Hong, R., Mishra,V. Effect of wealth inequality on chronic under-nutrition in Cambodian children. (2006) J Health Popul Nutr 24(1): 89-99.

23. Anderson, V.P., Jack, S., Monchy, D., et al. Co-existing micronutrient deficiencies among stunted Cambodian infants and toddlers. (2008) Asia Pac J Clin Nutr 17(1): 72-79.

24. World Health Organization and UNICEF Statistics Table. (2011).

25. Bachmeyer, M.H. Treatment of selective and inadequate food intake in children: A review and practical guide. (2009) Behav Anal Pract 2(1): 43-50.

26. National Institute of Statistics, Food security trend analysis report: Cambodia Socio-Economic Surveys 2004 and 2009. (2009) Ministry of Planning. 
27. Ecker, O., Diao, X. Food Security and Nutrition in Cambodia: Pattern and Pathways. (2011) a policy discussion paper. USAID special report 10.

28. Fujii, T. Micro-level estimation of child undernutrition indicators in Cambodia. (2010) The World Bank Economic Review 24(3): 520-553.

29. Kamiya, Y. Economic analysis on the socioeconomic determinants of child malnutrition in Lao PDR. (2009) Osaka School of International Public Policy, Osaka University.

30. Stevens, G.A., Finucane, M.M., Paciorek, C.J., et al. Trends in mild, moderate, and severe stunting and underweight, and progress towards MDG 1 in 141 developing countries: a systematic analysis of population representative data. (2012) Lancet 380(9844): 824-834.

31. Fujii, T. Micro-level estimation of child malnutrition indicators and its application in Cambodia. (2005) World Bank Policy Research Working Paper (3662).

32. Anderson, P.V., Cornwall, J., Jack, S., et al. Intakes from nonbreastmilk foods for stunted toddlers living in poor urban villages of Phnom Penh, Cambodia, are inadequate. (2008) Matern Child Nutr 4(2): 146159.

33. Miller, J.E., Rodgers, Y.V. Mother's Education and Children's Nutritional Status: New Evidence from Cambodia. (2009) Asian Development Review 26(1): 131-165.

34. Wiwanitkit, V., Sodsri, P. Underweight schoolchildren in a rural school near the Thai-Cambodian border. (2003) Southeast Asian J Trop Med Public Health 34(2): 458-461.

35. The World Bank. Nutrition at a glance: Cambodia.

36. Men, C.R., et al. Gender as a social determinant of health: Gender analysis of the health sector in Cambodia (2011).

37. Baum, F. The New Public Health. (2007) Third edition Australia: Oxford University Press.

38. Phnom Penh. Ministry of Planning, Poverty in Cambodia - a new approach: redefining the poverty line. (2013) Ministry of Planning.

39. Dimech, J. Think globally, act locally: Course And Immersion To Cambodia. (2012) Compass 46(2): 39-41.

40. Ikeda, N., Irie, Y., Shibuya, K. Determinants of reduced child stunting in Cambodia: analysis of pooled data from three Demographic and Health Surveys. (2013) Bull World Health Organ 91(5): 341-349.

41. Thielman, N., Ostermann, J., Whetten, K., et al. Correlates of Poor Health among Orphans and Abandoned Children in Less Wealthy Countries: The Importance of Caregiver Health. (2012) PLoS One 7(6):e38109.

42. Jacobs, B., Roberts, E. Baseline assessment for addressing acute malnutrition by public-health staff in Cambodia. (2004) J Health Popul Nutr 22(2): 212-219.

43. Marmot, M. Social determinants of health inequalities. (2005) Lancet 365(9464): 1099-1104.

44. Marriott, B.P., White, A., Hadden, L., et al. Infant Feeding in 20 Developing Countries with Focus on Infant Undernutrition in Cambodia. (2011) Handbook of Growth and Growth Monitoring in Health and Disease 1447-1469.

45. Richard, R. Maternal and Child Undernutrition 3: What works? Interventions for maternal and child undernutrition and survival. (2008) Child: Care Health and Development 34(3): 404-405.

46. Olney, D.K., Talukder, A., Iannotti, L.L., et al. Assessing impact and impact pathways of a homestead food production program on household and child nutrition in Cambodia. (2009) Food Nutr Bull 30(4): 355-369.

47. Harris, S., Jack, S. Home-based treatment of acute malnutrition in Cambodian urban poor communities. (2011) Food Nutr Bull. 32(4): 333-339.

48. Kamiya, Y. Socioeconomic Determinants of Nutritional Status of Children in Lao PDR: Effects of Household and Community Factors. (2011) J Health Popul Nutr 29(4): 339-348.

49 Haddad, L., Gillespie, S. Effective food and nutrition policy responses to HIV/AIDS: what we know and what we need to know. (2001) J Inter Develop 13(4): 487-511.

50. Labonte, R. Heart health inequalities in Canada: modules, theory and planning. (1992) Heart health inequalities in Canada: modules, theory and planning.

51. Keleher, H., McDougall, C. Understanding Health, edited by Helen Keleher \& Colin MacDougall. (2011): South Melbourne, Vic. Oxford University Press.

52. Hill, H., Menon, J. Reducing Vulnerability in Transition Economies: Crises and Adjustment in Cambodia. (2011) ASEAN Economic Bulletin 28(2): 134-159.

53. Pandey, S., Lin, Y., Collier-Tenison, S., et al. Social Factors Determining the Experience of Blindness among Pregnant Women in Developing Countries: The Case of India. (2012) Health Soc Work 37(3): 157-169.

54. Jayawardena, N., Subhi, R., Duke, T. The Western Pacific Regional Child Survival Strategy: Progress and challenges in implementation. (2012) J paediatr child health 48(3): 210-9.

55. Laverack, G. Public Health: Power, Empowerment and Professional Practice (2009). Palgrave Macmillan.

56. Bundara, N., Mwanri, L., Masika, J. Addressing childhood undernutrition in Tanzania: challenges and opportunities. (2013) African Journal of Food, Agriculture, Nutrition and Development 13(1): 7288-7306. 57. Ministry of Planning, Achieving Cambodia's Millennium Development Goals, (2011) Royal Government of Cambodia: Phnom Penh, Cambodia.

58. Bagriansky, J., Champa, N., Pak, K., et al. The economic consequences of malnutrition in Cambodia, more than 400 million US dollar lost annually. (2014) Asia Pac J Clin Nutr 23(4): 524-531.

59. Greffeuille, V., Sophonneary, P., Laillou, A., et al. Persistent Inequalities in Child Undernutrition in Cambodia from 2000 until Today. (2016) Nutrients 8(5).

60. Undernutrition in the land of rice - why there should be a nutrition goal in the post-2015 framework, the case from Cambodia. (2014) Results UK.

61. Rikimaru, T. What Are the Current Situations and the Challenges of Maternal and Child Malnutrition in Asia? (2015) J Nutr Sci Vitaminol (Tokyo) 61 Suppl: S63-65.

62. Wolde, M., Berhan, Y., Chala, A. Determinants of underweight, stunting and wasting among schoolchildren. (2015) BMC Public Health $15: 8$.
Online ISSN: 2377-0619

Journal Title: International Journal Food and Nutritional Science

Journal Short Name: Int J Food Nutr Sci
Ommega Online Publishers

E-mail: foodscience@ommegaonline.org

Website: www.ommegaonline.org 